\title{
Droplet Digital PCR Analysis of GSTM1 Deletion Polymorphism in Psoriatic Subjects Treated with Goeckerman Therapy
}

\author{
Martin Beránek ${ }^{1,2, *}$, Zdeněk Fiala ${ }^{3}$, Jan Kremláček ${ }^{4}$, Ctirad Andrýs ${ }^{5}$, Květoslava Hamákováb, \\ Vladimír Palička ${ }^{1}$, Lenka Borská
}

\begin{abstract}
${ }^{1}$ Institute of Clinical Biochemistry and Diagnostics, Charles University Hospital and Faculty of Medicine in Hradec Králové, Hradec Králové, Czech Republic

${ }^{2}$ Department of Biochemical Sciences, Charles University, Faculty of Pharmacy in Hradec Králové, Hradec Králové, Czech Republic

${ }^{3}$ Institute of Hygiene and Preventive Medicine, Charles University, Faculty of Medicine in Hradec Králové, Hradec Králové, Czech Republic

${ }^{4}$ Institute of Pathological Physiology, Charles University, Faculty of Medicine in Hradec Králové, Hradec Králové, Czech Republic

${ }^{5}$ Institute of Clinical Immunology and Allergology, Charles University, Faculty of Medicine in Hradec Králové, Hradec Králové, Czech Republic

${ }^{6}$ Clinic of Dermal and Venereal Diseases, Charles University Hospital Hradec Králové, Hradec Králové, Czech Republic

* Corresponding author: Institute of Clinical Biochemistry and Diagnostics, Charles University Hospital and Faculty of Medicine in Hradec Králové, Sokolská 581, 50005 Hradec Králové, Czech Republic, e-mail: beranek@lfhk.cuni.cz
\end{abstract}

Summary: Goeckerman therapy (GT) represents an effective treatment of psoriasis including a combination of pharmaceutical grade crude coal tar (CCT) and ultraviolet irradiation (UV-R). Coal tar contains a mixture of polycyclic aromatic hydrocarbons. The best known carcinogenic polyaromate - benzo[a]pyrene is metabolized into a highly reactive benzo[a] pyrene-7,8-diol-9,10-epoxide (BPDE). Glutathione S-transferase M1 (GSTM1) catalyses the conjugation of drugs, toxins and products of oxidative stress with glutathione. The aim of the study is to found possible associations between GSTM1 genotypes and the level of BPDE-DNA adducts in 46 psoriatic patients treated with GT. For genotyping, droplet digital PCR was applied. The GSTM1 copy number was normalized to $\beta$-globin reference gene. In five GSTM1*1/*1 subjects, the GSTM1 to $\beta$-globin ratio moved from 0.99 to 1.03 with a median of 1.01 . GSTM1*0/*1 heterozygotes $(\mathrm{n}=20)$ contained only one GSTM1 function allele which conditioned the ratio $0.47-0.53$ (median 0.50$)$. GSTMI*0/*0 individuals $(\mathrm{n}=21$ ) showed no amplification of the null variants because of the large deletion in GSTM1. BPDE-DNA concentrations ranged from 1.8 to $66.3 \mathrm{ng} / \mu \mathrm{g}$ with a median of $12.3 \mathrm{ng} / \mu \mathrm{g}$. GSTM1 $* 0 / * 0$ and $G S T M 1 * 0 / * 1$ genotypes showed non-significantly higher concentrations of BPDE-DNA adducts than the $G S T M 1 * 1 / * 1$ one $(12.3$ and $12.4 \mathrm{vs} 7.8 \mathrm{ng} / \mu \mathrm{g})$. The non-significant relationship between BPDE-DNA adducts and GSTM1 genotypes in psoriatic patients could be associated with relatively low doses of CCT and short-term UV-R exposures used in GT.

Keywords: GSTM1; Psoriasis; Goeckerman therapy; Genotyping; BPDE-DNA adducts

\section{Introduction}

Goeckerman therapy (GT) represents an effective treatment of psoriasis including a combination of pharmaceutical grade crude coal tar (CCT) ointment and ultraviolet irradiation (UV-R). This therapeutic approach is applied in cases of light to moderately severe forms of psoriasis (1). CCT contains a mixture of polycyclic aromatic hydrocarbons (PAHs). The best known carcinogenic polyaromate - benzo[a]pyrene $(\mathrm{BaP})$ is metabolized into a highly reactive benzo[a] pyrene-7,8-diol-9,10-epoxide (BPDE) and other reactive species.

The conjugation of $\mathrm{BaP}$ derivatives is catalyzed by glutathione S-transferases GSTM1 or GSTP1, and UDP glucuronosyltransferases $1 \mathrm{~A} 10,1 \mathrm{~A} 6,1 \mathrm{~A} 7 \mathrm{C}$ or 1A9. However, BPDE also intercalates in DNA by forming covalent bond with the nucleophilic guanine nucleotide bases at the N2 position and creates the BPDE-DNA adduct (2). GSTM1 (EC 2.5.1.18) is a cytosolic enzyme which catalyses the conjugation of drugs, toxins and products of oxidative stress 
with glutathione to form less reactive and more easily excreted water-soluble metabolites. To ensure high effectiveness of the conjugations, the GSTM1 gene (chromosome location 1p13.3) is expressed in a lot of human tissues including liver and skin (3).

Previously published papers showed that genetic polymorphisms in GSTM1 conditioned the individual response to electrophilic xenobiotic substances including PAHs. A large deletion (GSTM1 $* 0$ null variant) occurs hereditarily in about $50 \%$ of Caucasian population. The absence of active enzyme in subjects with the $G S T M 1 * 0 / * 0$ genotype declines the efficiency of detoxification processes and leads to genotoxicity, toxic encephalopathy, higher cutaneous ultraviolet radiation erythemal sensitivity and risk of asbestosis or cancer (4-10). It is apparent that the activity of GSTM1 influences the level of BPDE and hence also the level of BPDE-DNA adducts. However, the results of studies focused on relationships between the GSTM1 activity and the level of BPDE-DNA adducts, are still inconsistent (11-13). Moreover, only a little is known about genotoxic and mutagenic risks associated to GSTM1*0/*1 heterozygosity (10).

Genetic analysis of the GSTM1 deletion polymorphism is usually performed via Southern blotting, long range PCR, and real-time PCR with either SYBR Green or specific hydrolytic probes (14-17). All these methods distinguish the $G S T M 1 * 0 / * 0$ genotype from $G S T M 1 * 1 / *_{1}$ and $G S T M 1 * 0 / * 1$ ones. Quantitative real-time PCR enables separation of $G S T M 1 * 1 / * 1$ and $G S T M 1 * 0 / * 1$; both these genotypes featured by specific copy number reveal different values of cycle threshold $(C t)$. To normalize the input amount of genomic DNA, the $C t$ values are related to a reference gene with the constant copy number in the genome: albumin, $\beta$-globin or RNAse $P(10,18,19)$. Despite the use of sophisticated expectation-maximisation algorithms and precisely defined cut-off $C t$ intervals for $G S T M 1 * 1 / * 1$, $* 0 / * 1$ and $* 0 / * 0$, the results of trimodal genotyping are not clear and strictly depend on DNA quality and PCR amplification efficiency.

Droplet digital PCR (ddPCR) is a modern technology amplifying DNA separately in thousands of nanoliter-sized oil microdroplets. After PCR, the fluorescence of each droplet is recorded and the total number of events (droplets) above the threshold is counted. Here we describe a novel approach to GSTM1 genotyping based on droplet digital PCR. Using this technique we investigated a cohort of psoriatic patients treated with GT. In them, elevated level of BPDEDNA adducts were previously found (20).

\section{Material and Methods}

The cohort created a group of 46 patients with chronic stable plaque psoriasis treated with GT. The group consisted of 22 males and 24 females (average age of 48 years, age span 20-82 years; 23 smokers and 23 non-smokers). Within GT therapy, dermatological ointment containing 3\% of CCT was administered daily overnight on psoriatic lesions. Ac- cording to the extent of lesions, $18-62 \%$ of the total body surface was covered by CCT ointment. Each morning the residues of CCT were removed from the body (using oil bath) and the patients were whole-body irradiated by UV-R. The density of used radiation was $249.75 \mu \mathrm{W} / \mathrm{cm}^{2}$ of UV-B and $131.8 \mu \mathrm{W} / \mathrm{cm}^{2}$ of UV-A. The effectiveness of the therapy was calculated from basic characteristics of actual disease status (erythema, desquamation, and skin infiltration) and expressed as the PASI score (Psoriasis Area and Severity Index). The study was approved by the Ethics Committee of the Charles University Hospital in Hradec Králové, Czech Republic. Written informed consent was obtained from each patient.

EDTA-treated peripheral blood specimens were collected immediately after GT. Genomic DNA was extracted from $200 \mu \mathrm{L}$ of blood with a QIAamp DNA Blood Mini Kit (Qiagen, Germany). The level of BPDE-DNA adducts was determined by using the standard method OxiSelect BPDE-DNA Adduct ELISA Kit (Cell Biolabs, USA). The results were expressed in nanograms of BPDE-DNA adducts per microgram of DNA.

For genotyping, droplet digital PCR (QX100 Droplet Digital PCR System, Bio-Rad, USA) was applied. The GSTM1 copy number was normalized to $\beta$-globin reference gene. The amplification mix $(25 \mu \mathrm{L})$ contained $12.5 \mu \mathrm{L} 2 \times$ concentrated ddPCR Supermix (Bio-Rad, USA), $900 \mathrm{nM}$ of each primer, $250 \mathrm{nM}$ of hydrolysis fluorescent probes, and $100 \mathrm{ng}$ of DNA. The sequences of primers and probes were as follows: GSTM1 forward primer 5'-CAC CTG CAT TCG TTC ATG TGA C-3', GSTM1 reverse primer 5'-AAG CAA GAG CAG AGA GGA GAC-3', GSTM1 hydrolytic probe 5'-FAM-TTC AGT CCT GCC ATG AGC AGG CAC A-BHQ1-3', $\beta$-globin forward primer 5'-GAG GGT TTG AAG TCC AAC TCC TAA-3', $\beta$-globin reverse primer 5'- CAG GGT GAG GTC TAA GTG ATG ACA-3', and $\beta$-globin hydrolytic probe 5'-HEX-CAG TGC CAG AAG AGC CAA GGA CAG GT-BHQ1-3'.

The data were statistically processed by the R software version 3.22 using the "nortest" and "psych" packages. Because the Anderson-Darling test for the normality had rejected the hypothesis of a normal distribution of the BPDE-DNA adducts, nonparametric one-side Wilcoxon tests was used. Differences were considered to be statistically significant when $P<0.05$.

\section{Results and Discussion}

Droplet digital PCR enabled identification of all three genotypes. As illustrated in Fig. 1, there were no problems to evaluate the proper GSTM1 genotype if normalization to $\beta$-globin gene was performed. In five GSTM1*1/*1 subjects, the GSTM1 to $\beta$-globin ratio moved from 0.99 to 1.03 with a median of 1.01 proving the presence of two function alleles of GSTM1 in diploid cells. GSTM1 $* 0 / * 1$ heterozygotes $(\mathrm{n}=20)$ contained only one GSTM1 function allele which conditioned the ratio $0.47-0.53$ (median 0.50 ). GSTMI $* 0 / * 0$ 


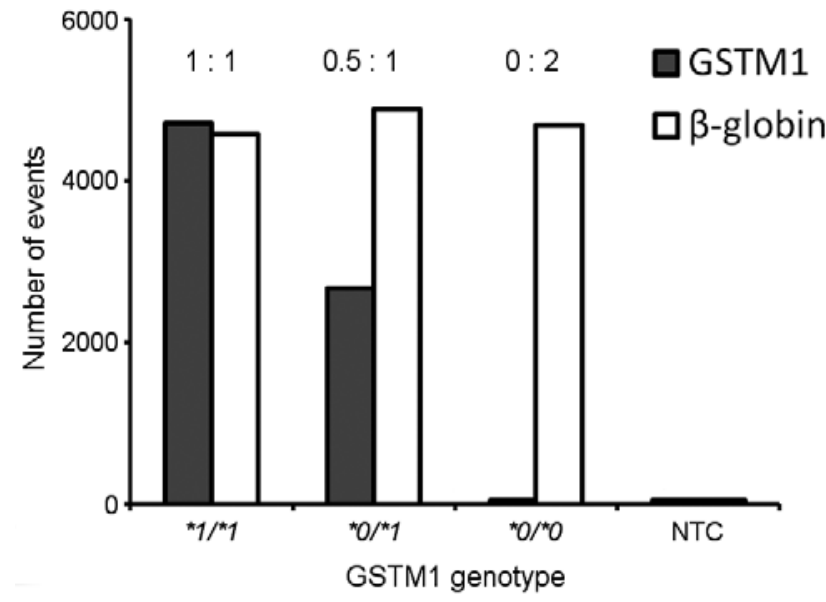

Fig. 1: The number of events recorded by ddPCR in different GSTM1 genotypes (black) normalized to $\beta$-globin gene (white). The proper GSTM1 to $\beta$-globin copy number ratio is indicated above the columns; NTC means no template control.

individuals ( $\mathrm{n}=21)$ showed no amplification of the null variants because of the large deletion in GSTM1.

The prevalence of $G S T M 1 * 0$ was 0.67 , and the genotype frequencies were in agreement with the Hardy-Weinberg equilibrium. The frequency of $G S T M 1 * 0$ determined in the patients agreed with the results of other studies $(10,18)$.

BPDE-DNA adducts were detected in all investigated blood specimens. Their concentrations ranged from 1.8 to $66.3 \mathrm{ng} / \mu \mathrm{g}$ with a median of $12.3 \mathrm{ng} / \mu \mathrm{g}$. No significant associations between the levels of adducts and sex or smoking were observed. GSTM1*0/*0 and GSTM1*0/*1 genotypes showed non-significantly higher concentrations of BPDE-DNA adducts in blood cells than the GSTM1*1/*1 one (median values 12.3 and $12.4 \mathrm{vs} 7.8 \mathrm{ng} / \mu \mathrm{g}$, Table 1 ). Combinating GSTMI*1/*1 and GSTM1*0/* 1 genotypes into one group, the difference in DNA adducts completely disappeared (median $12.2 \mathrm{ng} / \mu \mathrm{g} ; P=0.261$ ). This fact could clearly justify the importance of trimodal genotyping GSTM1.

Our data show that the concentrations of BPDE-DNA adducts in blood cells of psoriatic subjects in GT do not

Tab. 1: DNA adducts in GSTM1 genotypes.

\begin{tabular}{|c|c|c|c|c|}
\hline \multirow[t]{2}{*}{ GSTM1 genotypes } & \multirow[t]{2}{*}{$\mathbf{n}$} & \multicolumn{2}{|c|}{ 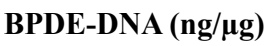 } & \multirow[t]{2}{*}{$P$} \\
\hline & & Median & Range & \\
\hline$G S T M 1 * 0 / * 0$ & 21 & 12.3 & $1.9-66.3$ & ref. \\
\hline GSTM1*0/*1 & 20 & 12.4 & $1.8-50.1$ & 0.329 \\
\hline GSTM1*1/*1 & 5 & 7.8 & $7.5-49.7$ & 0.227 \\
\hline $\begin{array}{l}\text { GSTM1*1/*1 } \\
\text { or } G S T M 1 * 0 / * 1\end{array}$ & 25 & 12.2 & $1.8-50.1$ & 0.261 \\
\hline
\end{tabular}

ref. reference group significantly associate with the GSTM1 genotype, though elevated levels of BPDE-DNA adducts in GSTM1* $0 / * 0$ and GSTM $1 * 0 / * 1$ carriers in comparison with the GSTM $1 * 1 / * 1$ were apparent.

We assume that this non-significant relationship could be associated with relatively low doses of CCT and shortterm UV-R exposures used in GT. In subjects exposed in industry to higher doses of PAHs, the relationship between BPDE-DNA adducts and GSTM1 was more evident $(11,12$, 21,22 ). Further, in parallel with GSTM1, the BaP derivates may also be conjugated by UDP glucuronosyltransferases to corresponding glucuronides. Therefore, if we assess the association between the GSTM1 activity and the level of BPDE-DNA adducts, we have to take into account the fact that we evaluate only a part of genetically conditioned processes of activation and deactivation of $\operatorname{BaP}(23,24)$. Finally, the skin of psoriatic patients was described to have lower GSTM1 catalytic activity than the normal skin (25). The loss of GSTM1 activity could lead to decreased expression of other GSTM isozyme (26) and to compensatory induction of other PAHs metabolizing enzymes, e.g., GSTP1 (27) or CYP1A1, especially in $G S T M 1 * 0 / * 0$ homozygotes $(11,28)$.

\section{Conclusions}

Droplet digital PCR has proved to be suitable for analysis of GSTM1 deletion polymorphism. At the group of psoriatic patients treated with GT, we found non-significant differences in the levels of BPDE-DNA adducts, roughly corresponding to genetic polymorphisms in GSTM1. Taking into account all the factors mentioned above, a larger population study evaluating the associations between BPDE-DNA adducts and other xenobiotic metabolizing enzyme polymorphisms in psoriatic patients should be performed.

\section{Acknowledgements}

This work is supported by the projects PRVOUK P37/09 and PRVOUK P37/11 of Charles University, Faculty of Medicine in Hradec Králové, Czech Republic.

\section{References}

1. Moscaliuc ML, Heller MM, Lee ES, Koo J. Goeckerman therapy: a very effective, yet often forgotten treatment for severe generalized psoriasis. J Dermatolog Treat 2013; $24: 34-37$

2. Borska L, Andrys C, Krejsek J, et al. Oxidative damage to nucleic acids and benzo(a)pyrene-7,8-diol-9,10-epoxide-DNA adducts and chromosomal aberration in children with psoriasis repeatedly exposed to crude coal tar ointment and UV radiation. Oxid Med Cell Longev 2014; 302528: 1-10.

3. Smith G, Ibbotson SH, Comrie MM, et al. Regulation of cutaneous drug-metabolizing enzymes and cytoprotective gene expression by topical drugs in human skin in vivo. Br J Dermatol 2006; 155: 275-281.

4. Kato S, Bowman ED, Harrington AM, Blomeke B, Shields PG. Human lung carcinogen-DNA adduct levels mediated by genetic polymorphisms in vivo. J Natl Cancer Inst 1995; 87: 902-907.

5. Soderkvist P, Ahmadi A, Akerback A, Axelson O, Flodin U. Glutathione S-transferase M1 null genotype as a risk modifier for solvent-induced chronic toxic encephalopathy. Scandinavian Journal of Work, Environment \& Health 1996; 22: 360-363.

6. Kerb R, Brockmoller J, Schlagenhaufer R, Sprenger R, Roots I, Brinkmann U. 
Influence of GSTT1 and GSTM1 genotypes on sunburn sensitivity. Am J Pharmacogenomics 2002; 2: 147-154.

7. Kelsey KT, Nelson HH, Wiencke JK, Smith CM, Levin S. The glutathione S-transferase theta and mu deletion polymorphisms in asbestosis. Am J Ind Med 1997 31: $274-279$.

8. Nakachi K, Imai K, Hayashi S, Kawajiri K. Polymorphisms of the CYP1A1 and glutathione S-transferase genes associated with susceptibility to lung cancer in relation to cigarette dose in a Japanese population. Cancer Res 1993; 53: 2994-2999.

9. Lear JT, Smith AG, Strange RC, Fryer AA. Detoxifying enzyme genotypes and susceptibility to cutaneous malignancy. Br J Dermatol 2000; 142: 8-15.

10. Nørskov MS, Frikke-Schmidt R, Bojesen SE, Nordestgaard BG, Loft S, Tybjærg-Hansen A. Copy number variation in glutathione-S-transferase T1 and M1 predicts incidence and 5-year survival from prostate and bladder cancer, and incidence of corpus uteri cancer in the general population. Pharmacogenomics J 2011 11: 292-299.

11. Brescia G, Celotti L, Clonfero E, et al. The influence of cytochrome P450 1A1 and glutathione S-transferase M1 genotypes on biomarker levels in coke-oven workers. Arch Toxicol 1999; 73: 431-439.

12. Topinka J, Sevastyanova O, Binkova B, et al. Biomarkers of air pollution exposure: a study of policemen in Prague. Mutat Res 2007; 624: 9-17.

13. Pastorelli R, Guanci M, Cerri A, et al. Impact of inherited polymorphisms in glutathione S-transferase M1, microsomal epoxide hydrolase, cytochrome P450 enzymes on DNA, and blood protein adducts of benzo(a)pyrene-diolepoxide. Cancer Epidemiol Biomarkers Prev 1998; 7: 703-709.

14. Roodi N, Dupont WD, Moore JH, Parl FF. Association of homozygous wild-type glutathione S-transferase M1 genotype with increased breast cancer risk. Cancer Res 2004; 64: 1233-1236.

15. McLellan RA, Oscarson M, Alexandrie AK, et al. Characterization of a human glutathione S-transferase mu cluster containing a duplicated GSTM1 gene that causes ultrarapid enzyme activity. Mol Pharmacol 1997; 52: 958-965.

16. Marín F, García N, Muñoz X, et al. Simultaneous genotyping of GSTT1 and GSTM1 null polymorphisms by melting curve analysis in presence of SYBR Green I. J Mol Diagn 2010; 12: 300-304.

17. Shi MM, Myrand SP, Bleavins MR, de la Iglesia FA. Highthroughput genotyping method for glutathione S-transferase T1 and M1 gene deletions using TaqMan probes. Res Commun Mol Pathol Pharmacol 1999; 103: 3-15.
18. Timofeeva M, Jäger B, Rosenberger A, et al. A multiplex real-time PCR method for detection of GSTM1 and GSTT1 copy numbers. Clin Biochem 2009; 42: 500-509.

19. Bediaga NG, Alfonso-Sánchez MA, de Renobales M, Rocandio AM, Arroyo M, de Pancorbo MM. GSTT1 and GSTM1 gene copy number analysis in paraffinembedded tissue using quantitative real-time PCR. Anal Biochem 2008; 378 221-223.

20. Borska L, Andrys C, Krejsek J, et al. Genotoxic and apoptotic effects of Goeckerman therapy for psoriasis. Int J Dermatol 2010; 49: 289-294.

21. Machado ML, Beatty PW, Fetzer JC, Glickman AH, McGinnis EL. Evaluation of the relationship between PAH content and mutagenic activity of fumes from roofing and paving asphalts and coal tar pitch. Fundam Appl Toxicol 1993; 21 : 492-499.

22. Topinka J, Binková B, Mracková G, et al. DNA adducts in human placenta as related to air pollution and to GSTM1 genotype. Mutat Res 1997; 390: 59-68.

23. Thomson Reuters - Life Sciences Research. MetaCore ${ }^{\mathrm{TM}}$. Benzo[a]pyrene metabolism. http://lsresearch.thomsonreuters.com/maps/2304/. January 2015.

24. Trushin N, Alam S, El-Bayoumy K, et al. Comparative metabolism of benzo[a] pyrene by human keratinocytes infected with high-risk human papillomavirus types 16 and 18 as episomal or integrated genomes. J Carcinog 2012;11: 1.

25. Smith G, Dawe RS, Clark C, et al. Quantitative real-time reverse transcriptionpolymerase chain reaction analysis of drug metabolizing and cytoprotective genes in psoriasis and regulation by ultraviolet radiation. J Invest Dermatol 2003; 121: 390-398.

26. Nakajima T, Elovaara E, Anttila S, et al. Expression and polymorphism of glutathione S-transferase in human lungs: risk factors in smoking-related lung cancer. Carcinogenesis 1995; 16: 707-711.

27. Hayes JD, Pulford DJ. The glutathione S-transferase supergene family: regulation of GST and the contribution of the isoenzymes to cancer chemoprotection and drug resistance. Crit Rev Biochem Mol Biol 1995; 30: 445-600.

28. Vaury C, Lainé R, Noguiez P, et al. Human glutathione S-transferase M1 null genotype is associated with a high inducibility of cytochrome P450 1A1 gene transcription. Cancer Res 1995; 55: 5520-5523.

Received: 31/05/2016

Accepted: 13/06/2016 